\title{
Drones Are Flying outside of Segregated Airspace in Poland
}

\section{New Rules for BVLOS UAV Operations}

\author{
Anna Konert ${ }^{1}$ (D) $\cdot$ Piotr Kasprzyk ${ }^{2}$ (D) \\ Received: 30 September 2019 / Accepted: 27 December 2019 / Published online: 17 January 2020 \\ (C) The Author(s) 2020
}

\begin{abstract}
Poland was one of the first European countries to adopt a national regulatory framework for the operation of drones. During its first years (2013-2016), the national regulator was more focused on VLOS operations, and BVLOS operations were possible only in segregated airspace. Since 2019, a new law has allowed for certain types of BVLOS operations to be conducted outside of segregated airspace, at very low levels. This paper will analyze how national legislation is dealing with this new technology, focusing on the new law on BVLOS operations. As the national regulation will be replaced in June 2020 by common European rules that have been adopted 2019, this paper also aims to highlight the most important provisions of the EU regulation.
\end{abstract}

Keywords drones $\cdot \mathrm{UAV} \cdot \mathrm{UAS} \cdot$ Polish regulations $\cdot$ EU regulations $\cdot$ air law

\section{Introduction}

New technologies have made the rapid development of the unmanned aircraft sector possible. However, as with every new technology, unmanned aircraft vehicles or systems (UAVs or UASs) possess their own regulatory and legal constraints. From a legal point of view, there are many questions to be answered under the general rules of law, such as privacy and personal data protection, public security, civil or criminal liability, etc. However, the main legal challenge is of a regulatory nature. The regulatory framework for UAV operations has to provide an adequate level of safety. In the case of UAVs, safety regulations aim to protect third parties on the ground and in the air as there are no crew or passengers on board of the aircraft.

Research financed by National Science Center, Poland. Project No 2017/ 27 /B/HS5/0008 "Unmanned Aircraft. A new era in aviation law".

Anna Konert

a.konert@lazarski.edu.pl

Piotr Kasprzyk

piotr.kasprzyk@cpk.pl

Institute of Air and Space Law, Lazarski University, Warsaw, Poland

2 Solidarity Transport Hub STH, Warsaw, Poland
There is no doubt that UAVs are considered to be aircraft under aviation law at international, regional (European Union) and national levels [1]. But the operation of unmanned aircraft is by definition different from the operation of manned aircraft. Therefore, it is almost impossible to apply existing aviation requirements to drones. For instance, a UAV cannot be issued with a type certificate or an individual airworthiness certificate, as certification standards have only been developed for manned aircraft categories. Also, other "traditional" aviation safety rules, i.e. for aircraft operations or crew licensing, were drafted with the fundamental assumption that there were crew members on board the aircraft. The presence of the crew enables the aircraft to avoid other aircraft under the applicable rules of the air. Therefore, it has been widely recognized that there is an essential need to create a new regulatory framework for drones and their operations. This new technology requires an innovative approach to be taken by policymakers and regulators.

The early stage of UAV development was situated within a military context. From a civil perspective however, when the first UAVs were tested for civil use, there were no standards or regulations regarding the design, production or operations of unmanned aircraft. This allowed the development and testing of new technologies, while at the same time prevented the use of unmanned aviation on a broader scale. The development of UAV regulations is, therefore, one of the major challenges for the future of aviation law. In particular, civil aviation safety regulations have to be a starting point for UAVs' regulatory development for at least two reasons. First, as was already 
noted, because aviation law recognizes a UAV as an aircraft. Second, because manned and unmanned aircraft operate within the same airspace.

In order to enable the safe operation of remotely-controlled aircraft, or even their operation by automated flight control systems (as part of what are called autonomous flights), the development of detailed solutions for a number of technical and operational aspects is essential up front. This includes, inter alia, the following issues:

- airworthiness standards for UAVs and UAS components;

- data transmission from the remote pilot station to the UAS (data link) including data link performance and protection against unauthorized interference;

- collision avoidance systems including motion and obstacle detection;

- reliability of drone location (e.g. GNSS) and emergency systems (e.g. loss of communication);

- unmanned traffic management systems,

- operator competences and training [2].

Developing a legal framework for a new technology is, by definition, a difficult task. New regulations require a thorough understanding of that technology, its possibilities, and limits. And, as it is a safety-related regulatory task, detailed knowledge of the associated risks is also necessary. Therefore, a riskbased and performance-based approach seems to be the most appropriate if regulation is to enable the safe operation and development of unmanned aviation. This goal requires a gradual integration of UAVs with the manned aviation that operates within the same airspace. Such integration is a long-term challenge for UAS technologies, but also requires some improvements in the field of manned aviation [3], especially in the domain of air traffic management.

A good example is the rules of the air. In most cases, UAVs are unable to comply with the rules of the air that were designed and developed for manned aviation that operates from aerodromes. For instance, with some exceptions (take-off and landing, emergency flights, state aviation operations), the rules of the air generally prohibit aircraft from flying below a certain height (150 $\mathrm{m}$ above the terrain). And most drones are designed to operate below that height. This is the case firstly because of their limited weight and endurance, and secondly, because it is a drones ability to operate very close to the ground or infrastructure that can create many business opportunities for new service providers. In other words, most of the available drones are designed to operate in the lower part of airspace that is underused by traditional aviation. Therefore, a new concept of operation is being developed for drones to allow them to operate not only within the prior segregated airspace. The idea behind this concept is to allow UAV flights to be conducted at very low heights as well as outside of aerodromes. It is in these parts of the airspace that manned aircraft operate only exceptionally. But existing rules of the air do not recognize this type of operation as they rely on the traditional division between visual and instrumental flight rules for pilots. Needless to say, but the rules of the air set forth the concept of "see and avoid" which requires pilots to maintain careful observation at all times, regardless of whether the operation is conducted under instrument or visual flight rules [4].

A regulatory framework for drones and their operations at a national or regional level usually starts with the regulation for operations of UAVs in so-called Visual Line of Sight Operations (VLOS), i.e. when direct visual contact is required with the UAV. Most countries have already taken the appropriate steps by adopting or developing their national legislation on the issue of the use of drones (usually up to $25 \mathrm{~kg}$ ) in VLOS operations. In most cases, such legislation precisely defines limits and restrictions for drone operations, e.g. by prohibiting operations in the vicinity of airports or by setting up the maximum distance between a drone and people or buildings.

Another step in the regulatory development is when the regulator allows some of the operations of UAVs in what is called Beyond Visual Line of Sight Operations (BVLOS). For safety and legal reasons, BVLOS operations are usually allowed only in segregated airspace. The main reason is of a technical nature, as there are no agreed standards for the essential components of the UAS, such as the command and control link, or detection and avoidance systems.

This paper will analyze the current regulations in Poland, focusing on the recent amendment, which entered into force on February 1st, 2019. Starting from that moment, some types of BVLOS UAV operations are allowed to fly beyond the segregated airspace. These operations are allowed at a very low level (up to $120 \mathrm{~m}$ above the terrain).

\section{The Regulatory Framework for UAV Operations in Poland}

\subsection{Amendment to the Aviation Law Act}

In 2011, an amendment to the Aviation Law Act [5] introduced the first provisions for UAVs into the national legal system in Poland. First of all, the Aviation Law Act states the general rule that flights of unmanned aircraft can be performed in Polish airspace (Article 126 Para 1). However, UAV flight is allowed when certain requirements for the UAV's equipment and operations are met (Article 126 Para 2 and 3 ). Those requirements should be specified in the implementing regulation issued by the Minister for Transport (Article 126 Para 5). If those requirements are not met, the UAV is only allowed to operate in segregated airspace that is not available for other air traffic (Article 126 Para 4). 
Soon enough, it became clear that the idea of drafting a regulation for all UAV operations at the national level was too ambitious. Needless to say, the first ICAO Circular on RPAS operations was published in 2011 [6]. After a few attempts to draft the implementing regulation on detailed rules for drone operations, the legislative process was terminated. But without that regulation (under Article 126 Para 5), it was impossible to operate UAV flights under the provisions of the Aviation Law Act even when certain requirements were met, simply because these requirements have not been published.

Therefore, two options were left under Aviation Law to allow drone operations.

First of all, under Article 126 Para 4, it was possible to conduct drone operations within segregated airspace.

Secondly, another regulatory task on implementing detailed rules for drones was launched, focusing on VLOS flights. But this new regulation was developed under a different legal basis than Article 126 of the Aviation Law Act.

Implementing regulation was issued under Article 33 of the Aviation Law Act of 2002 that allows the Ministry of Transport to exclude certain provisions of the Aviation Law Act for some types of aircraft that are not covered by EU safety regulations (standards). This legal basis has been used previously to regulate those types of aviation activities that cannot comply with general safety requirements based on international aviation standards, such as ultra-light aircraft or hang-gliders.

The legislative idea behind Article 33 of the Aviation Law Act is that the Minister of Transport shall be allowed to exempt some types of aircraft from the general provisions of the Aviation Law Act (i.e. the rules on airworthiness, the rules on operations, or the rules of the air). At the same time, the Minister shall publish detailed requirements for these aviation activities (which were exempted). This general provision allows some of the aviation activities to be kept under the general oversight of the civil aviation authority (CAA) and, at the same time, regulate those activities in a proportionate and flexible way.

\subsection{Implementing Regulation for VLOS Operations}

The Regulation of the Minister of Transport of March 26th, 2013 on the exclusion of certain provisions of the Aviation Law Act-for certain types of aircraft, and the specification of conditions and requirements for the use of these aircraft [7] was the very first attempt to regulate the general requirements for unmanned aircraft operations, which became one of the first national regulations on unmanned aircraft in Europe. The Regulation included detailed flight rules, as well as operator duties and responsibilities. This regulation was widely amended in 2016 [8], and the amendments were based on the practical experience of unmanned flights and their oversight. For instance, the first regulation of 2013 allowed only VLOS operations for UAVs with a mass of less than $25 \mathrm{~kg}$, but this limit was increased in 2016 to $150 \mathrm{~kg}$, when two additional, different sets of rules were implemented (as separate attachments to the implementing regulation). The first was for model aircraft that are UAVs that are only used for recreational or sport purposes (attachment 6). The second was dedicated to UAVs other than the models that are used mainly for commercial purposes (attachment 6a). Those rules allow UAVs to only perform VLOS operations. Moreover, the above-mentioned rules included a definition of VLOS operations - which are the operations in which the operator or observer of the flying model maintains direct eye contact with the flying model/unmanned aircraft [9].

\subsection{Implementing Regulation for BVLOS Operations}

For many years, BVLOS operations, according to Article 126 Para 4 of the Aviation Law Act, were only allowed in segregated airspace. Therefore, the operator was obliged to request Polish Air Navigation Services Agency (PANSA) to segregate such airspace for UAV BVLOS operations. In brief, there are two possibilities to segregate airspace under the general rules on airspace management regulation. The first allows PANSA to segregate airspace for ad hoc purposes at the operator's request. The second requires airspace segregation for longterm purposes, i.e. border guard patrols. Both procedures are quite complicated and were created a long time before UAV operation appeared on the scene. At the beginning, these procedures were used mainly for test flights or military purposes. After a few years, it became obvious that there was an essential need for new solutions for BVLOS operations. And again, the regulatory decision was made to use the "legislative vehicle" under article 33 of the Aviation Law Act for that purpose. The draft amendment to the Regulation of March 26, 2013, on the exclusion of certain provisions of the Aviation Law Act... was published in 2017 and was adopted the following year after a consultation process.

\section{BVLOS Operations According to the New Regulation}

A new Regulation was adopted on 20th December, 2018 and entered into force on 1st February, 2019 [10]. The regulation amended the Regulation of 2013 on the exclusion of certain provisions of the Aviation Law Act and added the new attachment $6 \mathrm{~b}$ with a complete set of rules to facilitate BVLOS operations [11].

The regulation addresses only drones with a start mass (take-off weight) of up to $25 \mathrm{~kg}$, and allows some BVLOS operations to be conducted outside of segregated airspace. Such flights can be operated only at a Very Low Level (VLL), that is, less than $120 \mathrm{~m}$ above ground level (AGL) with a maximum speed of $150 \mathrm{~km} / \mathrm{h}$. The height limit was 
introduced because the minimum height for manned aviation in uncontrolled airspace (class $\mathrm{G}$ ) is $150 \mathrm{~m}$ above the ground. But some flights are allowed to operate below that height, such as police and military operations, medical flights, operations from local airfields and emergency situations. And most of such flights take place within uncontrolled airspace, i.e. where Air Traffic Control service is not provided. This is why a number of limitations and requirements were introduced to minimize the risk to the manned aviation that sometimes operates at altitudes lower than $150 \mathrm{~m}$ above the ground.

First of all, BVLOS operations at VLL are allowed only in the case of the following flights: operational (for the needs of police, border guards, firefighting, health, search and rescue services, protection of state security); specialized (for the purposes of supervision, monitoring, control or protection, surveying, agriculture and forestry); automatic (for the needs of supervision, monitoring, control and protection, agrotechnical activities) and training.

Secondly, there are detailed provisions describing the duties and responsibilities of the UAV operator. In the first place, the operator shall avoid any action or omission that could compromise safety, hinder air traffic, disturb the public order or expose any person to harm. The operator shall also control the UAV in a manner that ensures that a collision with another aircraft or obstacle is avoided. The operator is also responsible for ensuring that the UAV under their control gives priority to manned aircraft.

Thirdly, a number of technical requirements were introduced. To minimize the risk to manned aviation, UAVs must be equipped with anti-collision lights and with barometer altitude equipment, as all manned aircraft are equipped. UAVs must also be equipped with a camera for observing its surroundings, which can minimize the risk of midair collision or collision with the ground. However, there are no detailed requirements for such cameras, there are also no strict requirements that indicate that UAVs must be equipped with detection and avoidance systems. Furthermore, a UAV must be equipped with devices or systems installed on-board or as a part of its ground equipment that enable it to maintain the planned flight parameters and conduct on-going monitoring of its flight parameters as well as to monitor the drone's basic parameters (location, speed, altitude, direction of flight). The UAV should also be able to record its flight parameters and to transmit its emergency location to the operator in the case of communication or control link failure. Moreover, such drones must be able to automatically perform emergency procedures, including: 1) proceeding the flight along a programmed route; 2) ending the flight by performing an emergency landing; 3) performing a flight to a pre-programmed location.

Another obligation is that BVLOS operators need to be authorized by the CAA. Such an authorization will be issued only when the operator provides a number of documents to the CAA including the operations manual describing, for example, how the operator minimizes risks during UAV operations. The first stage of the authorization process is the technical assessment of the UAV followed by the UAV registration in the state registry.

Last but not least, the operator is obliged to inform PANSA about its plan to perform a BVLOS flight 7 days in advance using a dedicated form or dedicated on-line system. Two days before the flight, PANSA will issue a NOTAM to inform the airspace users and Air Traffic Services (ATS) personnel. See an example of such a NOTAM below [12].

A3803/19 - NAVIGATION WARNING:OPERATIONS OF UNMANNED AERIAL VEHICLE (UAV) BEYOND VISUAL LINE OF SIGHT UP TO 90 M AGL BVLOS25) CTR EPWA. ACFT: SP-YYXX, SP-YYYY.

LATERAL LIMITS (WGS-84):

RADIUS 500 M CENTERED ON: 520805 N 0210537E. VERTICAL LIMITS:

LOWER LIMIT: GND.

UPPER LIMIT: 570FT AMSL.

CONTACT: $+48,570,357,357$. GND - 570FT AMSL, 0600-1800, 03 SEP 06:002019 UNTIL.

30 Sep 18:002019. Created: 22 Aug 14:382019

The regulation also provides the legal basis to create and operate UAVs with a so-called Unmanned Traffic Management System. Such system should facilitate the exchange of the necessary information between UAV operators, pilots and air traffic services personnel.

For obvious reasons, BVLOS flights will require additional approval to allow for operations within military airspace, aerodrome traffic zones, restricted zones etc. as well as for those airspaces which are restricted for security reasons.

It must also be stressed that flying UAVs into controlled airspace (such as the CTR around an airport) in BVLOS operation will be allowed only if the operator meets all applicable conditions defined by air traffic services provider (PANSA).

Besides detailed provisions for BVLOS operations at VLL, the regulation also defines the term "automatic flight" as a flight on a programmed route without the participation of the operator, but with the capability to immediately take over the remote control. Automatic flights are allowed to be performed and can be carried out up to $50 \mathrm{~m}$ above ground level (AGL) or up to an altitude of $10 \mathrm{~m}$ above the highest obstacle within a radius of $100 \mathrm{~m}$ from the place of where the operation started, and at a horizontal distance of at least $150 \mathrm{~m}$ from settlements and other population centers.

\section{Safety and Legal Challenges}

The new regulation creates new opportunities for the UAV sector in Poland. But new possibilities for unmanned aircraft create safety challenges for manned aviation as well as for third parties. It is too early to assess the new regulation. 
During the first seven months of it being in force, CAA authorized more than 40 operators for BVLOS, and PANSA has published more than 160 information (NOTAMs) allowing to conduct BVLOS operations flights under the new rules, most of them being training flights. However, there are some serious doubts regarding the risk that the new type of UAV operations can pose to manned aircraft and to the people and property on the ground.

It must be underlined that the new regulation allows BVLOS UAV operations to be performed outside of segregated airspace when operating a UAV that can weight up to $25 \mathrm{~kg}$. Only a few European countries have adopted similar regulations, but have done so with much stronger limitations. For instance, in France and Spain, such operations are allowed only for UAVs that weigh less than $2 \mathrm{~kg}$ [13]. However, in Spain, UAVs with a mass up to $25 \mathrm{~kg}$ can operate in BVLOS operation outside of segregated airspace when equipped with the approved detection and avoidance systems [14]. Similar regulations are applied in the UK, where operators are required to apply an approved method of aerial separation and collision avoidance as a prerequisite for BVLOS operation [15].

Under the Polish regulation, a detection and avoidance system is not mandatory equipment for UAVs that are operated in BVLOS operations outside of segregated airspace. It seems that the decision about the use of such critical equipment was left by the regulator for the operator level. Of course, the operator's decision has to be followed by a safety assessment process, but this assessment is not subject to authority approval. Therefore, the lack of a clear legal requirement on a detection and avoidance system as part of compulsory UAV equipment is one of the main loopholes within the regulation.

A detection and avoidance system seems to be a critical technical solution to mitigate the risk of a mid-air collision. A similar problem arises with the avoidance of obstacles, terrain and moving objects.

And when it comes to the risk of a mid-air collision, a serious issue concerns general aviation aircraft that often operate without an engine and depend on meteorological conditions, such as balloons, gliders and paragliders. First of all, such activities in Poland are still popular among aviation users. And, aircraft such as gliders and paragliders are simply more vulnerable to damage in the case of a potential mid-air collision involving a drone [16]. Moreover, when operating in non-controlled airspace, pilots are not obliged to use radio communication, so it is often the case that flight information services are not provided to them.

It is also worth mentioning that without any equipment that allows for identification and avoidance of other aircraft and obstacles, it can be a challenge for a drone operator to follow the instructions from military or police aircraft in the case of interception.
Another question is how the operator will avoid other drones, especially those which are operating under VLOS. It is still unclear if drone operators are obliged to read NOTAMs as a legal obligation, as they are addressed to pilots in the rules of the air. Of course, most drone operators use some applications, but such applications usually provide specific data without taking any legal responsibility for its accuracy.

Moreover, a general remark arises. The regulation introduces many requirements, but does not specify how they are to be met. For instance, a communication and data link is required. However, it is not specified what parameters are sufficient to acknowledge that there is ensured communication that allow continuation of the flight. Another example is that the drone location should be provided during the operation, but no detailed parameters (e.g. accuracy) were specified.

Therefore, the basic conclusion made after analyzing the regulation is the need to verify this approach. While a performance-based approach is justified, and the regulator sets the goals for the operators, there was no indication of the means to check whether these goals has been achieved. If the regulator, who defines the goals, does not want to specify detailed parameters, it should specify at least procedures for checking how the operator intends to meet these goals, as well as what parameters it can demonstrate.

This means that the regulation should clearly require the operator to show through a risk assessment processes what specific solutions (supported by evidence) were used to achieve the required goals. The risk assessment process regarding the key safety requirements of each operation should be the subject of an assessment done by the CAA. Key safety requirements in this respect should concern at least:

- how the communication with the UAV and its control is provided (C2 link),

- how the UAV location data is provided,

- how the airspace is observed and collisions avoided,

- how emergency procedures work.

This assessment should be done prior to the issuance of the authorization to the operator by the CAA.

This is more or less the approach that was adopted in the new EU legislation, which will gradually replace national regulations from mid-2020.

\section{EU Regulatory Framework Development}

In 2014, the European Commission published a Communication entitled "A new era for aviation. Opening the aviation market to the civil use of remotely piloted aircraft systems in a safe and sustainable manner" [17]. A legislative process aimed at the extension of EU competences for the safety regulations for drones and their operations was launched in 
2015. In the opinion of the EU institutions, the existing differences between national regulations are hampering the market growth of the UAS sector. When the European Parliament and the Council were shaping the final draft on the new common rules for aviation safety, the European Union Aviation Safety Agency (EASA) launched its own rulemaking task to prepare future implementing rules to be ready when the mandate to regulate drones is finally given to the EU. This mandate was finally adopted on 11th September 2018, when the new Regulation of the European Parliament and of the Council on common rules for aviation safety was published [18].

Based on the formal proposal from the EASA [19], the European Commission published a regulation on 11th June 2019, covering almost all aspects of drones and their operations. The EU regulation consists of two separate European Commission acts. The first is Delegated Regulation No 2019/945 of 12 March 2019 on unmanned aircraft systems [20], and sets out the requirements for the design and manufacture of drones intended for the Open category [defined below]. The second act is Implementing Regulation no 2019/947 of 24 May 2019 on the rules and procedures for the operation of unmanned aircraft [21]. The new regulation will gradually become applicable starting from a year after publication. By 2022, the transitional period will be completed and the regulation will be fully applicable. Starting in June 2020, the EU regulations will replace the national regulations that vary across the member states. To facilitate the harmonized implementation of those regulations, EASA published, in October 2019, so-called acceptable means of compliance (non-binding standards) and guidance materials (non-binding materials) to Implementing Regulation no 2019/947 [22].

Next year is therefore a transition period. While still operating under national regulations, drone operators are required to prepare themselves for the EU regulations that will apply in a uniform way across member states. The approach, the terminology and the requirements used at the EU level are quite different to the national regulations, as they were drafted for all EU Member States. And what should also be stressed is that the EU regulation introduces the general obligation to register drone operators at the national level.

The regulation is intended to follow three basic concepts: operation-centric, risk-based and performance-based. The operations of UASs at the EU level are classified into three categories.

The Open category of operations presents a low risk or no risk to third parties, and therefore does not require a prior authorization nor a declaration by the operator before the operation takes place. In general, this category is limited to UASs that weight no more than $25 \mathrm{~kg}$, operate only in VLOS (or extended VLOS) at a height less than $120 \mathrm{~m}$ above the ground.
Another is the Specific category, which presents a greater risk than that of the Open category, or where one or more elements of the operation fall outside of the Open category. Operations within the Specific category require an operational risk assessment followed by an authorization issued by the CAA. Some exceptions are foreseen for some types of operations (so-called standard scenarios) and for some kinds of UAS operators (so-called "light UAS operators").

The EU regulations focus on the Open and Specific categories. The third category, the so-called Certified category, will be regulated at a later date with specific requirements for UAS certification, operator approvals, and remote pilot training and licensing. The EASA foresees that the first draft of the Certified category will be published in 2020. It must be underlined that the Certified category is foreseen for those UASs that meet one of the following conditions:

1) it has a characteristic dimension of $3 \mathrm{~m}$ or more, and is designed to be operated over groups of people,

2) it is designed for transporting people,

3) it is designed for the purpose of transporting dangerous goods.

\section{BVLOS Flights in the Specific Category}

It has already been explained that the Open category is bounded by three main factors, and one of them is that the UAV must be operated within VLOS. This means that all BVLOS flight are by default classified within the Specific category, unless they meet the criteria for the Certified category. Operation in the Specific category requires operational authorization from the CAA, which is based on a safety risk assessment.

In order to avoid different interpretations of Article 11 of Implementing Regulation no 2019/947, which details the elements to be considered when carrying out a risk assessment, the EASA recommendation is to use the SORA methodology developed by a group of experts called JARUS (Joint Authorities for Rulemaking on Unmanned Systems) [23].

This methodology is a kind of guidance for a UAS operator and its CAA in the process of determining how severe a risk the UAV operation poses and whether it can be conducted in a safe manner. The SORA methodology is based on the principle of a holistic system safety model that is used to evaluate the risk related to a given UAV operation.

In order to facilitate the activities of the UAS operator when applying for an operational authorization in the Specific category, another EASA recommendation is to use a so-called predefined risk assessment (PDRA), that is, a pre-application of the SORA methodology for a defined UAS operation in the preparatory process. As of October 2019, the PDRA 
application is foreseen by the EASA only for operations with the following main attributes:

1) UAV with a maximum characteristic dimension up to $3 \mathrm{~m}$ and a typical kinetic energy up to $34 \mathrm{~kJ}$,

2) operated BVLOS of the remote pilot with visual air risk mitigation (UAV is not operated more than $1 \mathrm{~km}$ from the remote pilot or the observer),

3) conducted over sparsely populated areas, less than $150 \mathrm{~m}$ above the ground and in uncontrolled airspace.

The regulation foresees two exceptions, for which authority approval is not required for operation in the Specific category, namely a "light UAS operator certificate" and a standard scenario declaration.

A so-called "light UAS operator" may operate under a certificate issued by the authority. Such a certificate privileges the UAS operator to authorize its own operation, however it requires the operator to establish a number of safety management processes as part of a safety management system. The operator must demonstrate its capabilities and compliance with the applicable requirements before a light UAS operator certificate will be granted.

The regulation also introduces the "standard scenario" concept for some relatively simple types of operation. Such a scenario is defined as a type of UAS operation in the specific category, for which a precise list of mitigation measures has been identified in such a way that the competent authority can be satisfied with the declaration in which the operators declare that they will apply the mitigating measures. In other words, for such a "standard scenario," the safety risk assessment has already been conducted by the regulator (EASA) and the risk mitigation measures were published (in the form of the appendix to the regulation describing detailed requirements). The operator who decides to conduct such an operation must follow all of the published conditions and limitations for the standard scenario. From a legal point of view, an authorization is not required, but the operator has to submit a formal declaration to the CAA that they will follow the standard scenario requirements.

The first two types of UAS operations proposed for the standard scenarios are:

1) Urban VLOS in a populated environment; and

2) Rural BVLOS in sparsely populate areas.

Drafts for those two standard scenarios were published by EASA at the end of 2019, and they will need to go through the legislative process of the revision of Implementing Regulation no 2019/947.

In summary, an analysis of the new EU regulations regarding BVLOS operations leads to the conclusion that the regulations at the EU level are based on a different approach to national regulations such as those in force in Poland. On the one hand, it is apparent that the EU regulations are the result of a long-term legislative process aimed at creating uniform rules for the use of drones at the regional rather than the national level. On the other hand, however, it is unclear whether, on an EU scale, UAV operators are prepared enough to operate in a regulatory environment based on risk analysis and the newly developed methodologies for assessing this risk. It is, therefore, to be expected that the so-called standard scenarios were published, which more or less come down to the detailed requirements and restrictions that the operator will be required to use in a given type of operation.

\section{The effects of the EU regualations in poland}

Assuming that the Polish provisions regarding BVLOS operations are not changed, starting from June 2020, in Poland two legal regimes for BVLOS operations would apply.

The first one is the European Commission regulation2019/947 implementing rules that qualify BVLOS flights asa "specific operation" category. For such operations, in orderto indicate which requirements are necessary to keep theoperation safe (including - in some cases - segregation ofthe airspace), a thorough risk assessment should beconducted. Moreover, the competent authority shall evaluatethe risk assessment and the robustness of the mitigatingmeasures that the operator proposed to keep operation safein all phases of the flight. Operational authorization isgranted, provided that the outcome of risk assessment is acceptable.

However, for state UAS operation s, the national regulationof the Ministry of Transportation analysed in the paper willbe applicable. A large number of BVLOS operations withUAS of mass up to $25 \mathrm{~kg}$, flying with a maximum speed ofup to 150 $\mathrm{km} / \mathrm{h}$, will be based on a risk analysis performedby the operator, but without being assessed by the competentauthority. National regulation requires an operator only toinclude risk analysis procedures into an operational manual.However, the competent authority is not obliged to asses anindividual risk analyses.

Only for this reason, the question of whether we would notdeal with a justified case mentioned in Art. 3 of the BasicRegulation can be raised. That brings us to the conclusionthat without making any changes to the national regulation,it may be necessary to separate state BVLOS UASoperations from other aircraft operations, including UASoperated under EU implementing rules. 


\section{Conclusion}

Thanks to user-friendly regulations and a step-by-step approach, Polish airspace has become more accessible to drone operators. The operational experience which was been gathered under the national legislation has allowed for the building of a drone "airmanship", and this will be helpful in the preparation for the new EU common rules in the future. On the other hand, there are still some safety concerns about BVLOS operations outside of segregated airspace.

Obviously, the question arises whether the amendment to the national regulation of 2019 makes any sense, since in mid2020, EU regulations comprehensively regulating UAV operations will come into force. By reason of the principle of the primacy of EU law over national law, as soon as EU regulations on drones enter into force, national rules will, as a rule, lose their force.

However, it should be remembered that by expanding the EU's competence in the field of aviation safety regulation of drones, the general principle was left that these regulations do not apply to broadly understand state aviation.

Article 3 sub. 2 of the Regulation of the European Parliament and of the Council on common rules for aviation safety (Basic Regulation) states that "this Regulation shall not apply to aircraft... while carrying out military, customs, police, search and rescue, firefighting, border control, coastguard or similar activities or services under the control and responsibility of a Member State, undertaken in the public interest by or on behalf of a body vested with the powers of a public authority, and the personnel and organisations involved in the activities and services performed by those aircraft."

Therefore, Member States may leave their national laws on drones in force if they relate to the use of drones in missions that are carried out by or to state entities. The Polish regulator, allowing BVLOS flights under the new rules in 2019, has limited them to specific types of flights, including operational flights that correspond more or less the definition of state aviation operation used in the Basic Regulation.

The Basic Regulation, however, allows Member States to extend the application of EU rules on the safety of drone operations also to state aviation operations (Article 3 sub 6 of the Basic Regulation). Pending such a decision being taken and notified to the European Commission, national law will still be applied to drone operations on public missions.

Therefore, if the decision to extend EU drone regulations to missions carried out by the public sector is not taken, then a revision of the national law on drone flights out of sight seems necessary.

However, if the national legislator decides not to revise this regulation, leaving to the operator the key decisions for BVLOS flights (such as the detection and avoidance system, or specific requirements for the $\mathrm{C} 2$ link), the possibility of performing drone operations on public missions outside of designated areas will be debatable.

Article 3 of the Basic Regulation imposes on Member States the obligation to ensure that activities and services performed by state aircraft are carried out with due regard to the safety objectives of this Regulation. And, most importantly, it requires Member States to ensure, where appropriate, that those aircraft are safely separated from other aircraft.

Open Access This article is licensed under a Creative Commons Attribution 4.0 International License, which permits use, sharing, adaptation, distribution and reproduction in any medium or format, as long as you give appropriate credit to the original author(s) and the source, provide a link to the Creative Commons licence, and indicate if changes were made. The images or other third party material in this article are included in the article's Creative Commons licence, unless indicated otherwise in a credit line to the material. If material is not included in the article's Creative Commons licence and your intended use is not permitted by statutory regulation or exceeds the permitted use, you will need to obtain permission directly from the copyright holder. To view a copy of this licence, visit http://creativecommons.org/licenses/by/4.0/.

\section{References}

1. B.I. Scott (red.), The Law of Unmanned Aircraft Systems. An Introduction to the Current and Future Regulation under National, Regional and International, Kluwer Law International, The Netherlands, 2016

2. P.Kasprzyk and A.Konert, Unmanned aircraft. A new era for aviation. A new era for aviation law?, Coventry Law Review no $12 /$ 2018.

3. See more in ICAO RPAS CONOPS (March 2017) and EUROCONTROL RPAS ATM CONOPS (Ed. 4.0, 2017)

4. Anderson, Ernest E., et al. "A Legal Analysis of 14 C.F.R. Part 91 See and Avoid Rules to Identify Provisions Focused on Pilot Responsibilities to See and Avoid in the National Airspace System." Journal of Air Law and Commerce, vol. 80, no. 1, Winter 2015, p. 53-238. HeinOnline

5. Journal of Laws from 2002 No 130, Item 1112 with further amendments. See also M. Żylicz (ed.), Prawo lotnicze. Komentarz (Air Law Commentary). Warsaw 2016

6. Unmanned aircraft systems. Cir 328. AN/190.

7. Journal of Laws from 2013, Item 440.

8. Journal of Laws from 2016, Item 1317.

9. For VLOS operations see more A.Konert \& M.Kotliński, Polish regulations on Unmanned Aerial Vehicles, Transportation Research Procedia, Volume 35, 2018, Pages 140-147 (https:// www.sciencedirect.com/science/article/pii/S2352146518303624)

10. Journal of Laws from 2019, Item 94.

11. English translation of the Attachment $6 \mathrm{~b}$ was published on the CAA website [access on 06/05/19] http://ulc.gov.pl/pl/publikacje/ wiadomosci/4551-tlumaczenie-zalacznika-6b-do-rozporzadzeniaz-art-33-ust-2-i-4-ustawy-prawo-lotnicze

12. via https://www.notams.faa.gov

13. LOI ${ }^{\circ} 2016-1428$ du 24 octobre 2016 relative au renforcement de la sécurité de l'usage des drones civils (JORF n 0249 du 25 octobre 2016) (Law n ${ }^{\circ} 2016-1428$ of October 24th, 2016 on the reinforcement of the safety of the use of civil drones)

14. Real Decreto $1036 / 2017$, de 15 de diciembre, por el que se regula la utilización civil de las aeronaves pilotadas por control remoto, y 
se modifican el Real Decreto 552/2014, de 27 de junio, por el que se desarrolla el Reglamento del aire y disposiciones operativas comunes para los servicios y procedimientos de navegación aérea y el Real Decreto 57/2002, de 18 de enero, por el que se aprueba el Reglamento de Circulación Aérea. (BOE Núm. 316 Viernes 29 de diciembre de 2017) (Royal Decree 1036/2017, of December 15, which regulates the civil use of drones and amending Decree 552/2014)

15. CAP 722: Unmanned Aircraft System Operations in the UK Airspace - Guidance https://publicapps.caa.co.uk/docs/33/CAP\% 20722\%20Sixth\%20Edition\%20March\%202015.pdf (Access: 8. 02.2019)

16. EASA Drone Collision Task Force Report (2016), see also https:// udayton.edu/blogs/udri/18-09-13-risk-in-the-sky.php

17. COM/2014/0207 final

18. Regulation (EU) 2018/1139 of the European Parliament and of the Council of 4 July 2018 on common rules in the field of civil aviation and establishing a European Union Aviation Safety Agency (OJ L 212, 22.8.2018, p. 1-122)

19. EASA Opinion 1-2018 followed by the A-NPA 2015-10 and NPA 2017-05

20. Official Journal of the EU of 11.06.2019, L152/1

21. Official Journal of the EU of 11.06.2019, L152/45

22. Executive Director Decision 2019/021/R

23. http://jarus-rpas.org/content/jar-doc-06-sora-package [acces on 06/05/19]

Publisher's note Springer Nature remains neutral with regard to jurisdictional claims in published maps and institutional affiliations.
Prof. Anna Konert is currently the Dean, Faculty of Law and Administration, as well as an Air LawProfessor, Director of Institute of Air \& Space Law, Lazarski University, Warsaw, Poland. Sheobtained her Ph.D. at the Faculty of Law and Administration of the Nicolaus Copernicus University inTorun (2009) and was awarded the post-doctoral degree at the Faculty of Law and Administration ofthe Nicolaus Copernicus University in Torun (2015). Dr. Konert has been a Lecturer at LazarskiUniversity Faculty of Law and Administration since 2009. Her research areas include aviation law,space law, civil law (liabilities), European law, and international law. Honorary member of theEuropean Aviation Club (since 2014). Her professional and social memberships include Director ofthe Institute of Air and Space Law (since 2014); Vice President of the Polish Aviation Club (2013-2016); and Member of the Board of the European Air Law Association (since 2013). Dr. Konert iswidely published and an expert on RPAS.

Piotr Kasprzyk has a Ph.D. in Law, is an Attorney at Law, and a Research Fellow at the Institute ofAir and Space Law at Lazarski University in Warsaw, Poland. Dr. Kasprzyk is also the Head of theLegal Department of a new central airport for Poladn (Solidarity Transport Hub). He is also the formervice-president for aviation standards of the Civil Aviation Authority in Poland, and a formerplenipotentiary for air navigation standards at the Polish Air Navigation Service Agency. He is anactive member of the European Air Law Association, providing legal support for airlines, aircraftoperators and owners, airport operators, air navigation service providers, aero clubs, air trafficcontrollers and pilot's unions. Dr. Kasprzyk has 12 years of experience in Aviation Law and 20 yearsof experience in aviation as a private pilot. 